\section{Has Hospital Pharmacy Passed Its Peak?}

\section{THE "PRO" SIDE}

There is little doubt that pharmacy as a profession is currently in a period of renaissance. More than ever before, pharmacists are assisting individuals to achieve optimal drug therapy outcomes and are using new tools to facilitate patientcentred care, such as the authority to prescribe medications. ${ }^{1-3}$ But what of hospital pharmacy practice specifically? Is it well suited for continued growth, or has it hit a "glass ceiling"?

As rising expenditures threaten the sustainability of Canada's health care system, governments are working hard to ensure that they receive value for each dollar spent. ${ }^{4}$ Health care professionals are dealing with threats to the status quo, such as alternative payment models, expanded scopes of practice, ${ }^{5}$ and new service delivery models. ${ }^{6}$ Hospital pharmacy is not immune to these changes, and we argue here that although hospital pharmacy practice may not have reached its full potential, it has peaked, because an increased emphasis on primary health care is shifting the burden of chronic disease management from hospital-based teams to community-based teams. This shift will lead to a narrower, acute care role for hospital-based clinicians, while offering expanded opportunities for primary care pharmacy clinicians.

\section{What Does the Peak of Practice Look Like?}

In 1971, George Provost, editor of the American Journal of Hospital Pharmacy (now the American Journal of HealthSystem Pharmacy), wrote "It seems likely that health care delivery in the future will emphasize preventive and ambulatory care and will attempt to keep patients out of hospital beds. For this reason it is entirely possible that hospital pharmacy, as it is known today, may already have reached or passed its peak. Pharmacy of tomorrow, although it might be institution-based, may be practiced largely in a different type of controlled, multidisciplinary environment in which patients are offered comprehensive health maintenance services on an outpatient basis." Given that Provost made his prediction over 40 years ago, it becomes critical to define the "peak" of hospital pharmacy practice. Individual opinions may vary, but we suspect that common themes would mirror those outlined in the CSHP 2015 initiative, ${ }^{8}$ namely, having a safe, technicianrun drug distribution system that allows pharmacists to focus their efforts on optimizing medication use as integrated members of the health care team.

\section{So, Has Hospital Practice in Canada Peaked?}

At this point, you may be thinking that hospital pharmacists have come a long way in demonstrating the impor- tant contributions that they can make to patient care,,$^{2,9}$ but the most recent Hospital Pharmacy in Canada survey, ${ }^{8}$ as well as reports from Alberta indicating suboptimal uptake of pharmacist prescribing in hospital practice, ${ }^{10}$ suggest that there is still a way to go. However, we argue that it's not achievement of the "ideal practice" that defines the professional peak. Rather, to use an analogy from the economic world, the peak of a market cycle is a milestone that is seen as the height of achievement, but only in retrospect, after the bubble has burst. Thus, although it may not feel like hospital practice has peaked, in trying to make predictions about the future, it is important to analyze key market indicators for warning signs that suggest threats to future growth to determine if stock in hospital pharmacy should be bought, sold, or held.

\section{Increased Focus on Primary Care Renewal}

Beyond the report of the Commission on the Future of Health Care in Canada ${ }^{11}$ and statistics highlighting the burden that chronic disease is placing on the Canadian health care system, ${ }^{12}$ valuable insights can be found by evaluating the impact of primary care renewal on health care delivery in both the United States and the United Kingdom. Many would argue that Canadians have little to learn from US-style health care, which is the most expensive in the world and lacks equity. ${ }^{13}$ However, there are several examples of high-performing integrated systems in the United States, and one of their consistent features is a strong and well-integrated primary care sector. ${ }^{14-16}$ Redesign in the health care system administered by the US Department of Veterans Affairs, including increased emphasis on primary care, has resulted in dramatic improvements in quality of care, patient satisfaction, and efficiency, while reducing per patient expenditures. ${ }^{17}$ The Geisinger Health System and Group Health Cooperative have reported how the patient-centred medical home model can improve access and outcomes, while reducing hospital visits and readmissions for ambulatory care sensitive conditions. ${ }^{15,16}$ In the United Kingdom, the National Health Service is another topperforming system, ${ }^{18}$ a main component of which is strong primary care infrastructure with needed services being delivered in the community. ${ }^{19}$

\section{Decreased Emphasis on Hospital Care in Canada}

Hospital care makes up the largest component of health care spending in Canada, ${ }^{4}$ and governments recognize that continued growth in acute care is not sustainable. To address hospital capacity and wait time issues, Alberta Health Services is pursuing strategies to reduce lengths of stay and increase the provision of care in Primary Care Networks and Family Care Clinics. ${ }^{20}$ This type of experiment is not, nor will it be, limited to Alberta. ${ }^{18}$ 


\section{Primary Care Practice is Desirable to Pharmacists!}

Over the past 5 years, there has been increased demand for primary care pharmacists across Canada. These positions allow pharmacists to develop relationships with other members of the health care team and to access patients' complete medical records. They have all the desirable features previously thought to be the domain of hospital pharmacy, with the added bonus that pharmacists can develop long-term relationships with patients. Unlike positions in hospital or community pharmacies, these primary care positions are entirely patient-focused and are free from the "distraction" of drug distribution. Just think of it: no "disp" shifts! Although the emergence of primary care practice may not decrease interest in hospital practice, data from the United Kingdom suggest that many primary care pharmacists have a hospital pharmacy background. ${ }^{21}$ No Canadian data are available yet, but this shift may represent a potential "brain drain" for hospital pharmacy.

\section{Conclusion}

We will always have hospitals, and there will always be a cohort of pharmacists who get "supercharged" by the thrill of working in the intensive care unit or on the internal medicine service. However, investor sentiment is moving toward primary care, and all signs indicate that pharmacists are figuring this out. While the authors applaud and respect the efforts of the excellent pharmacy clinicians within our health care institutions, we are certain that Provost's vision has finally become a reality. Investors cannot actually buy and sell stock in hospital pharmacy practice; if they could, however, and on the basis of the indicators presented above, our position would be to "sell". Leaders in the profession would be foolish to invest their efforts solely in trying to bring all acute care hospitals up to $100 \%$ compliance with "dream" practice, at the expense of ignoring rapidly developing opportunities in primary care.

\section{References}

1. Nkansah N, Mostovetsky O, Yu C, Chheng T, Beney J, Bond CM, et al. Effect of outpatient pharmacists' non-dispensing roles on patient outcomes and prescribing patterns. Cochrane Database Syst Rev. 2010;(7):CD000336.

2. Kaboli PJ, Hoth AB, McClimon BJ, Schnipper JL. Clinical pharmacists and inpatient medical care: a systematic review. Arch Intern Med. 2006; 166(9):955-64.

3. Emmerton L, Marriott J, Bessell T, Nissen L, Dean L. Pharmacists and prescribing rights: review of international developments. J Pharm Pharm Sci. 2005;8(2):217-25.

4. National health expenditure trends, 1975 to 2012. Ottawa (ON): Canadian Institute for Health Information; 2012 [cited 2013 Feb 4]. Available from: https://secure.cihi.ca/free_products/NHEXTrendsReport2012EN.pdf

5. Nurse practitioner-led clinics. Toronto $(\mathrm{ON})$ : Ontario Ministry of Health and Long-Term Care; [updated 2012 Jun 27; cited 2013 Feb 4]. Available from: www.health.gov.on.ca/transformation/np_clinics/np_mn.html

6. Care transformation. Edmonton (AB): Alberta Health Services; [cited 2013 Feb 4]. Available from: www.albertahealthservices.ca/services.asp?pid= service\&rid=1054602

7. Provost GP. Clinical pharmacy and hospital pharmacy [editorial]. Am J Hosp Pharm. 1971;28(1):17.

8. Borenstein C. CSHP 2015. In: Babich M, Bornstein C, Bussières JF, Hall K, Harding J, Lefebvre P, et al., editors. Hospital pharmacy in Canada 2009/2010 report. Eli Lilly; 2010 [cited 2013 Feb 4]. p. 84-95. Available from: www. lillyhospitalsurvey.ca/hpc2/content/2010_report/chapter_i\%20.pdf

9. Bond CA, Raehl CL, Patry R. Evidence-based core clinical pharmacy services in United States hospitals in 2020: services and staffing. Pharmacotherapy. 2004;24(4):427-40.
10. Hutchison M, Lindblad A, Guirguis L, Cooney D, Rodway M. Survey of Alberta hospital pharmacists' perspectives on additional prescribing authorization. Am J Health Syst Pharm. 2012;69(22):1983-92.

11. Romanow RJ, chair. Building on values: the future of health care in Canada. Final report. Saskatoon (SK): Commission on the Future of Health Care in Canada; 2002 [cited 2013 Mar 11]. Available from: http:// publications.gc.ca/collections/Collection/CP32-85-2002E.pdf

12. Nasmith L, Ballem P, Baxter R, Bergman H, Colin-Thomé D, Herbert C, et al. Transforming care for Canadians with chronic health conditions: put people first, expect the best, manage for results. Ottawa (ON): Canadian Academy of Health Sciences; 2010.

13. Public Policy Committee of the American College of Physicians, Ginsburg JA, Doherty RB, Ralston JF Jr, Senkeeto N, Cooke M, Cutler C, et al. Achieving a high-performance health care system with universal access: what the United States can learn from other countries. Ann Intern Med. 2008;148(1):55-75.

14. Kates N, Hutchison B, O'Brien P, Fraser B, Wheeler S, Chapman C. Framework for advancing improvement in primary care. Healthc Pap. 2012;12(2):8-21.

15. Reid RJ, Fishman PA, Yu O, Ross TR, Tufano JT, Soman MP, et al. Patientcentered medical home demonstration: a prospective, quasi-experimental, before and after evaluation. Am J Manag Care. 2009;15(9):e71-87.

16. Gilfillan RJ, Tomcavage J, Rosenthal MB, Davis DE, Graham J, Roy JA, et al. Value and the medical home: effects of transformed primary care. Am J Managed Care. 2010;16(8):607-14.

17. Kizer KW, Dudley RA. Extreme makeover: transformation of the veterans health care system. Annu Rev Public Health. 2009;30:313-39.

18. Baker GR, MacIntosh-Murray A, Porcellato C, Dionne L, Stelmacovich K, Born K. Learning from high-performing systems: quality by design. In: High performing healthcare systems: delivering quality by design. Toronto (ON): Longwoods Publishing Corporation; 2008 [cited 2013 Feb 4]. p. 11-26. Available from: www.longwoods.com/content/20133

19. Baker GR, MacIntosh-Murray A, Porcellato C, Dionne L, Stelmacovich K, Born K. Birmingham East and North Primary Care Trust and Heart of England Foundation Trust-Birmingham, UK. In: High performing healthcare systems: delivering quality by design. Toronto (ON): Longwoods Publishing Corporation; 2008 [cited 2013 Feb 4]. p. 27-64. Available from: www.longwoods.com/content/20135

20. Ministerial directives: immediate results, long term sustainability. Summary report. Edmonton (AB): Alberta Health Services: 2012 Nov 8 [cited 2013 Feb 4]. Available from: www.albertahealthservices.ca/rls/ne-rls-2012-11-08ministerial-directives-summary-report.pdf

21. Silcock J, Raynor DK, Petty D. The organisation and development of primary care pharmacy in the United Kingdom. Health Policy. 2004; 67(2):207-14.

\section{Mark Makowsky, BSP, PharmD}

Faculty of Pharmacy and Pharmaceutical Sciences

University of Alberta

Edmonton, Alberta

Tania Mysak, BSP, PharmD

Alberta Health Services

Edmonton, Alberta

Competing interests: None declared.

\section{THE "CON" SIDE}

Many famous, but erroneous, predictions have been made in the health care literature. One noted example was the 1967 prediction of then-US Surgeon General William H Stewart that it was "time to close the book on infectious diseases and declare 
the war against pestilence won". Just as hindsight has shown the ill-considered nature of this statement, so too has George Provost's prediction of the demise of hospital pharmacy ${ }^{2}$ proven ill-founded. Not only has hospital pharmacy practice continued to grow in its complexity and importance, but there is no clear "peak" in sight for the future of practice in this field.

The aging of the Canadian population is putting pressure on both ambulatory and institutional care environments. Although a tremendous amount of work is being done to improve care for patients in the home, this trend may result in greater acuity and greater need for careful medication management among those patients who are admitted to acute care.

The effectiveness of team-based care has been proven in the hospital environment, ${ }^{3-5}$ and this setting remains best suited for the provision of this type of patient care. Interdisciplinary care creates a team-teaching environment that lends itself to continual learning for all team members and easily enables pharmacists to build the trust of the health care team. Pharmacists on rounds manage drug therapy proactively, having an impact at the point of decision-making, not through a reactive mechanism (when faced with a prescription in the community) or by referral in a multidisciplinary team (such as may occur in a primary care setting). When pharmacists are integrated into the process of care, strong relationships with patients are also built. Even though these relationships may be short-lived or interrupted, they are meaningful to patients with chronic illnesses, as noted in our colleague Mark Makowsky's own study. ${ }^{6}$

Hospital pharmacists have proven themselves consistent and unfaltering leaders in the profession, serving as trailblazers in practice innovation for patient-centred care, interprofessional teams, and independence in prescribing. Hospital pharmacists identified themselves as prescribers more than 20 years ago, through therapeutic drug monitoring, anticoagulation management, and therapeutic interchange programs. This early adoption of prescribing activities demonstrates the trust earned by hospital pharmacists in advance of pharmacists in other settings. That trust was confirmed in 2007 by correspondence between the Canadian Society of Hospital Pharmacists (CSHP) and the Canadian Medical Association (CMA) after Alberta pharmacists received prescribing rights. Then-president of the CSHP, Carolyn Bornstein, wrote to then-president of the CMA, Brian Day, following a CMA General Council meeting where the majority voted against an expanded role for pharmacists in managing and monitoring patients' medication therapy. ${ }^{7}$ Day's reply ${ }^{8}$ revealed that the CMA position was in fact focused on community-based care. Day commended hospital pharmacists for their role in collaborative settings, stating that hospital pharmacists are widely respected for their contributions to patient care. $^{8}$

Alberta was the first province to formally grant pharmacists prescribing privileges more broadly. As of January 24, 2013, 83 hospital pharmacists and 18 pharmacists in continuing care had attained Alberta's Additional Prescribing Authorization (D Cooney, Deputy Registrar, Alberta College of Pharmacists; personal communication by e-mail, January 24, 2013). This number might seem low until you consider that only $20 \%$ of the roughly 4400 pharmacists in Alberta practise in an institutional setting. As such, there are already $11.5 \%$ of hospital pharmacists using their additional prescribing rights. In contrast, 74 pharmacists in ambulatory clinics, 108 in community practice, and 46 in primary care have attained Additional Prescribing Authorization, for a combined rate of $6.5 \%$ or about half that of hospital pharmacists. Although it is apparent that Additional Prescribing Authorization has not been fully adopted by either hospital or community pharmacists, it should also be noted that Alberta Health Services has only recently endorsed a policy allowing pharmacists to prescribe in the institutional setting (effective January 31, 2013). ${ }^{9}$ Hospital pharmacists are already working ahead of the curve, and expectations are high that numbers will continue to climb with this endorsement. Prescribing by pharmacists also streamlines the collaborative care that these health care professionals provide as they manage medications for patients admitted to, transferred through, and discharged from acute and long-term care facilities.

The argument for an increased role for pharmacists in ambulatory settings is based on the assumption that, as public health and disease prevention strategies improve, patients will receive more of their care in the community. However, empowering patients to take responsibility for their own health and providing pharmacists with the ability to provide an elevated level of service in the community does not always lead to better health outcomes. For example, only about $20 \%$ of Albertans received their influenza vaccination in the 2012/2013 season, ${ }^{10}$ despite many community pharmacists becoming actively involved in immunization campaigns. The subsequent outbreaks created a huge strain on the hospital system, similar to what was seen elsewhere in the country. Indeed, although community pharmacists seem to be in the ideal location to provide proactive preventive services, the fact remains that the time they spend with patients providing these services competes directly with the time they spend dispensing medications. Until this product focus is removed, community practice cannot become fully patient-centred. ${ }^{11}$ Even if time constraints in dispensing did not affect their ability to provide care, community pharmacists would still face additional barriers, such as limited access to patient records and laboratory test results, that would result in a loss of familiarity with and comfort in managing these important patient care tools soon after graduation or completion of a continuing professional development program. As pharmacy technicians take on new roles in dispensing, pharmacists in community settings will be better supported to provide more direct patient care. However, many institutions are also prepared to take advantage of the expanding technician scope and move more pharmacists into additional (higher-acuity) direct patient care roles. There is certainly no time to simply "ride the wave" in an ever-evolving and expanding hospital practice!

We fully acknowledge the increasing prevalence of primary care, family health teams, and other ambulatory settings where pharmacists can practise and agree that these are exciting new opportunities for our community colleagues. However, we 
maintain that when pharmacy's community partners look for examples of interdisciplinary team collaboration and evidence of positive patient outcomes through these partnerships, they will continue to look to hospital pharmacists.

\section{References}

1. Bristol N. Obituary: William H Stewart. Lancet. 2008;372(9633):110.

2. Provost GP. Clinical pharmacy and hospital pharmacy [editorial]. Am J Hosp Pharm. 1971;28(1):17.

3. Bond CA, Raehl CL. Clinical pharmacy services, pharmacy staffing, and hospital mortality rates. Pharmacotherapy. 2007;27(4):481-93.

4. Makowsky MJ, Koshman SL, Midodzi WK, Tsuyuki RT. Capturing outcomes of clinical activities performed by a rounding pharmacist practicing in a team environment: the COLLABORATE Study. Med Care. 2009; 47(6):642-50.

5. Makowsky MJ, Schindel TJ, Rosenthal M, Campbell K, Tsuyuki RT, Madill HM. Collaboration between pharmacists, physicians and nurse practitioners: a qualitative investigation of working relationships in the inpatient medical setting. J Interprof Care. 2009;23(2):169-84.

6. Rosenthal M, Makowsky MJ, Tsuyuki RT, Madill HM. Patient's perspectives on team-based care by a clinical pharmacist: case report. Can J Hosp Pharm. 2010;63(1):38-40.

7. Bornstein C. The role of pharmacists in collaborative care teams [open letter]. Ottawa (ON): Canadian Society of Hospital Pharmacists; 2007 Oct 2 [cited 2013 Jan 28]. Available from: www.cshp.ca/dms/dmsView/ 1_Letter-to--CMA-on-ltrhead.pdf

8. Day B. Response to letter from C. Bornstein [open letter]. Ottawa (ON): Canadian Society of Hospital Pharmacists; 2007 Nov 30 [cited 2013 Jan 28]. Available from: www.cshp.ca/dms/dmsView/1_Letter-from-CMA.PDF
9. Pharmacist prescribing of medication orders [policy]. Edmonton (AB): Alberta Health Services; 2013 Jan 9 [cited 2013 Jan 31]. Available from: www.albertahealthservices.ca/hp/if-hp-phys-clin-policy-pharmacistprescribing-of-medications.pdf

10. Alberta respiratory virus surveillance report. Update for flu week 4 (Jan 20-26, 2013). Edmonton (AB): Alberta Health Services; 2013 Jan 30 [cited 2013 Jan 31]. Available from: www.albertahealthservices.ca/poph/hipoph-surv-resp-virus-current.pdf

11. Rosenthal MM, Breault RR, Austin Z, Tsuyuki RT. Pharmacists' selfperception of their professional role: insights into community pharmacy culture. J Am Pharm Assoc. 2011;51(3):363-7.

\section{Jill Hall, BScPharm, ACPR, PharmD}

Clinical Assistant Professor

Faculty of Pharmacy and Pharmaceutical Sciences

University of Alberta

Edmonton, Alberta

Margaret Gray, BSP

Clinical Practice Leader

Pharmacy Services

Alberta Health Services

Edmonton, Alberta

Competing interests: Jill Hall is a member of the Continuing Competence Committee of the Alberta College of Pharmacists. Margaret Gray is Vice Chair of the Continuing Competence Committee of the Alberta College of Pharmacists and Junior Chair of the Advocacy Committee of the Canadian Society of Hospital Pharmacists.

\begin{tabular}{lcc} 
& Advertisers & IndeX \\
\hline & \multicolumn{1}{c}{ Ad Page } & Prescribing Information \\
\hline Astellas / Oncology & 80 & - \\
\hline CATIE / Publications & 145 & - \\
\hline Health Canada / Medeffect & 83 & - \\
\hline Hospira / Gemcitabine & IFC & - \\
\hline Pfizer / Injectables & 78 & - \\
\hline Pharmaceutical Partners of Canada / Corporate & OBC
\end{tabular}

